effect on flower initiation but on vegetative growth. Neither bud abscission nor female sterility could be shown to be simple day-length effects, but both appear to be induced primarily by low temperatures, in conjunction, perhaps, with long days in the case of abscission, and short days in the case of style abortion.

\section{Reorganization of Root Apices after Irradiation}

UNDER this title F. A. L. Clowes has described experiments in which roots were irradiated with $\mathrm{X}$-rays and then fed with adenine $-8 \cdot{ }^{14} \mathrm{C}$ at various intervals afterwards to observe the effect of the radiation on the sites of deoxyribonucleic acid synthesis and hence on the behaviour of the meristem (Annals of Botany, N.S., 23, 205 (1959)). Dividing meristem cells may be so badly damaged that they stop synthesizing deoxyribonucleic acid and dividing; and when this occurs root growth may continue by the formation of a new meristem. The latter often originates in the quiescent centre, the cells of which do not normally synthesize deoxyribonucleic acid or divide. These apparently constitute a reservoir of cells which are less vulnerable because of their quiescence; but are able to restart deoxyribonucleic acid synthesis and division when the normally meristematic cells cease to do so. Because of this re-organization of the apex, Clowes considers that it is not legitimate to argue about the behaviour of normal root meristems from chimeras induced by irradiation.

\section{Palæotemperatures and the Origin of the Deep Sea Fauna}

A CRITICaL review of the methods of determination of the temperatures of ancient seas by the measurement of the oxygen isotopes ratio in fossil calcareous organisms is given by $\mathbf{Y}$. A. Birstein (Priroda, 5, $21 ; 1959$ ). It is based partly on the work published in the Soviet Union and it leads to certain new ideas regarding the origin of the deep sea fauna. Thus the author of this review is casting doubt upon the conclusions of C. Emiliani and C. Edwards (Nature, $171,887 ; 1953)$, regarding the sharp changes of sea temperatures during the late Tertiary era, and also about those of A. Fr. Bruun (Nature, 177, 1105; 1956) regarding the extinction of the deep sea fauna. According to the author all the deep oceanic regions must be considered to be regions of a relatively constant temperature, affording a place of refuge to many animal species which have eventually died out in the waters of a lesser depth.

\section{Liquation Differentiation in Magma}

A NEW contribution to one of the most controversial problems in petrology-liquation differentiation - was made by V. I. Lebedinsky (Priroda, 12, 99 ; 1958); whose original paper, which he wrote in collaboration with Mo Ke-Min, was published separately (Bull. Acad. Sci. U.S.S.R., Sér Géol., 12, 64; 1958). In these two papers the authors describe certain peculiar liparite lavas from the Kalgan region of Northern China. The lavas in question contain spherulites and spherulitic aggregates, made of a fibrous mineral. The chemical analysis of the spherulites differs from that of the ground-mass in which they are immersed by a greater amount of silica, soda and potash, and a lower amount of magnesia, lime and water. The author suggests that this rock is a solidified emulsion formed by the separation of the original magma into two immiscible liquid fractions.
A number of petrologists deny the possibility of liquation in natural magmas, although there are a number of experimental results published proving that in certain cases such a phenomenon does occur. Such are, for example, the papers by D. P. Grigoriev (1935), D. P. Grigoriev and F. V. Iskyul (1937), J. W. Greig $(1927,1928)$, O. F. Tuttle and I. I. Friedman (1948) and E. Roedder (1951). On the other hand, there are also numerous works dealing with spherulitic rocks and spherulites as developed in commercial glasses. Beginning with the classical studies by A. Lagorio (1887), many petrologists were attracted by this subject. A number of them, like F. Y. Loewinson-Lessing $(1884,1905,1935)$ and T. L. Tanton (1925), tried to prove that certain spherulitic rocks were indeed products of magmatic liquation. On the other hand, there were many petrologists, such as, for example, D. S. Belyankin (1933, 1949), who has studied both spherulitic rocks and spherulitic commercial glasses, who do not believe in magmatic liquation, and would attribute the spherulitic structure to devitrification in the solid state.

\section{Medicina Experimentalis}

AlthougH some think there are already too many scientific journals-and people! -in the world, the birth of a new one is always an interesting event. Medicina Experimentalis is the name which has been given to the latest arrival, to be published by $\mathrm{S}$. Karger, and to be devoted to experimental medicine in its widest sense (Medicina Experimentalis, 1, No. 1, 1959. International Journal of Experimental Medicine. Pp. $i i+68$. Six numbers per volume (two volumes annually). Subscription price per volume : 56 Swiss francs. Basel and New York : S. Karger, 1959). The foreword deplores the tendency of research workers "to shut themselves up hermetically in their ever narrowing specialist circles" and states that the aim of the sponsors is to provide a completely international journal which will cover the wide-and ever widening-fields of experimental physiology, pathology and therapeutics and help to bridge the gap between their multiplying specialities. Papers will be published in English, French and German and are to be limited to an overall length represented by 10,000 words. Authors will rarely be allowed to exceed this and will be charged for the excess. In return for this restriction on the verbosity of their clients, the editors promise to publish the papers submitted within three months. In these days of specialization and editorial congestion, these aims are laudable but may be rather difficult to achieve, and the small international conferences which have become so popular may be a better way of dealing with the frustrations of slow publication in parts of the world where they can be conducted successfully in a single language. The first number contains eight papers in German and one each in French and English. As the foreword says, the new journal will be what readers and authors make it. We wish it well.

\section{Improved Gunmetals}

THE Mond Nickel Co., Ltd., has announced the production of a new alloy for gunmetal : $85 / 6 \cdot 5 / 3 / 3 \cdot 5 / 2$, copper $:$ tin $:$ zinc $:$ lead $:$ nickel. It is claimed that it has better mechanical properties at both atmospheric and elevated temperatures than $85 / 5 / 5 / 5$ gunmetal and still retains the same adapt. ability to the production of pressure-tight castings. When properly made, castings in this alloy have a $0 \cdot 1$ per cent proof stress of around 8 tons/sq. in. with 